\title{
Adult low-risk drinkers and abstainers are not the same
}

Janette Mugavin $^{1 *} \mathbb{D}$, Sarah MacLean ${ }^{1,2}$, Robin Room ${ }^{1,3}$ and Sarah Callinan ${ }^{1}$

\begin{abstract}
Background: Alcohol consumption, even at low-levels, can not be guaranteed as safe or risk free. Specifically, the 2009 Australian National Health and Medical Research Council drinking guidelines recommend that adults should not drink more than two standard drinks on any day on average, and no more than four drinks on a single occasion. Nearly $40 \%$ of Australians aged 12 years and older drink alcohol but don't exceed these recommended limits, yet adult low-risk drinkers have been largely overlooked in Australian alcohol survey research, where they are usually grouped with abstainers. This paper examines the socio-demographic profile of low-risk drinking adults (18+ years old), compared to those who abstain.

Methods: Data from the 2013 National Drug Strategy Household Survey were used. In the past 12 months, 4796 Australians had not consumed alcohol and 8734 had consumed alcohol at low-risk levels, accounting for both average volume and episodic drinking (hereafter low-risk).

Results: Multivariate logistic regression results indicated that low-risk drinkers were more likely to be older, married, Australian-born, and reside in a less disadvantaged neighbourhood compared with abstainers. There was no significant difference by sex between low-risk drinkers and abstainers.

Conclusions: The socio-demographic profile of low-risk drinkers differed from that of abstainers. Combining lowrisk drinkers and abstainers into a single group, which is often the practice in survey research, may mask important differences. The study may support improved targeting of health promotion initiatives that encourage low-risk drinkers not to increase consumption or, in view of increasing evidence that low-risk drinking is not risk free, to move towards abstinence.
\end{abstract}

Keywords: Adults, Low-risk drinking, Abstinence, Socio-demographics, Cross-sectional data

\section{Background}

The prevalence of alcohol consumption is high among Australians, with $75 \%$ of the population aged 12 years and older having consumed at least one Australian standard drink ( $10 \mathrm{~g}$ ethanol) in the previous year [1]. National sources also state that most adults drink at low to moderate levels $[1,2]$. Low-risk drinking is defined two ways in the 2009 National Health and Medical Research Council (NHMRC) drinking guidelines: drinking no more than two Australian standard drinks per day, on average, to reduce the lifetime risk of alcohol-related chronic disease (i.e., lifetime low risk); and drinking no more than four standard drinks to reduce the risk of acute harms arising

\footnotetext{
* Correspondence: J.Mugavin@latrobe.edu.au

${ }^{1}$ Centre for Alcohol Policy Research, School of Psychology and Public Health,

La Trobe University, Bundoora, Victoria 3086, Australia

Full list of author information is available at the end of the article
}

from a single drinking occasion (i.e., single occasion low risk). These guidelines are directed towards persons aged 18 years and older (i.e., of legal drinking age); younger Australians, particularly those aged 15 and under, are advised to abstain from alcohol [3].

Recent estimates suggest that 58\% of Australians aged 12 years and over drink alcohol at lifetime low-risk levels, and on the measure of single occasion risk, 39\% drink at low-risk levels. Accounting for both guidelines, $37 \%$ drink alcohol within recommended levels [4]. Lowrisk drinking is common among older adults, and with Australia's ageing population [5], understanding the profile of this group may become more important.

However, alcohol consumption, like many other modifiable behaviours, is not risk free, with recent studies suggesting that amounts as small as half a standard drink (i.e.,

(c) The Author(s). 2020 Open Access This article is distributed under the terms of the Creative Commons Attribution 4.0 International License (http://creativecommons.org/licenses/by/4.0/), which permits unrestricted use, distribution, and reproduction in any medium, provided you give appropriate credit to the original author(s) and the source, provide a link to the Creative Commons license, and indicate if changes were made. The Creative Commons Public Domain Dedication waiver (http://creativecommons.org/publicdomain/zero/1.0/) applies to the data made available in this article, unless otherwise stated. 
$5 \mathrm{~g})$ daily is associated with an increase in cancer risk [6]. Outside of morbidity and mortality work, few Australian studies differentiate between alcohol abstainers and lowrisk drinkers or consider differences in demographic characteristics of the two groups. Even less is known about the attributes of low-risk drinkers who neither drink at levels associated with long-term nor short-term harm. Many Australian studies investigating the association between socio-demographic dimensions and alcohol use among adults have focused on elevated levels of drinking and the potential of long-term harm [7], short-term harm [8, 9], or both [10-13]. In such analyses, the exact configuration of the group to which risky drinkers are compared is often unclear $[7,8,10,12]$. When information is provided, the comparison group typically includes both abstainers and non-risky drinkers [11].

Australian studies that differentiate between abstainers, low-risk drinkers and risky drinkers, and report sociodemographic correlates associated with alcohol use, tend to pool teenagers and adults together [14] or focus on a subset of adults based on sex $[15,16]$, age $[17-20]$ or other characteristics (e.g., ethnicity) [21]. Consequently, socio-demographic information about Australian adults who drink alcohol, but do so at low levels, is limited.

Similarly, non-Australian studies have examined the socio-demographic correlates of abstainers, light or moderate drinkers and heavier drinkers, though they typically focus on discrete groups such as men [22] or an age cohort $[23,24]$. Furthermore, direct comparisons between abstainers and low-risk drinkers is the exception rather than the rule [25]. Overall, these studies do provide some insights into social demographic differences between abstainers and low-risk drinkers. For example, a Finnish twin study found that former drinkers had a lower annual income, and they also spent less time per year in gainful employment over a 20-year period compared with moderate drinkers [26]. In this study, the measure of moderate drinking was comparable to the 2009 NHMRC long-term low-risk threshold. These studies examine attributes associated with one or more types of low-risk drinking but, as is the case with Australian-based studies, low-risk refers to either average total volume or episodic drinking and not to those who meet both criteria.

In this paper we address whether the socio-demographic characteristics of adult low-risk drinkers differ from those who did not consume alcohol in the past year. This is important in the current policy context as cultural-political assumptions in Australian thinking tend to favour the ideal of low-risk drinking as a goal. The long twentieth-century reaction against temperance [27] has meant that abstention from alcohol is still unexpected and even questionable in many social circles, while 'low-risk drinking' is the explicit ideal, for instance, in the Australian drinking guidelines [3], and the implicit ideal in such government campaigns as the National Binge Drinking Strategy of 2008-2012 [28]. But who the low-risk drinkers are, especially those who drink within both the NHMRC guidelines, and whether or not they have the same socio-demographic characteristics as abstainers remains unanswered by the current literature.

\section{Methods \\ Sample}

Data were taken from the 2013 National Drug Strategy Household Survey (NDSHS), a nationally representative, cross-sectional survey of Australians aged 12 years and older [29]. A multi-stage stratified sampling design was used to randomly select residential households from across Australia, and one resident (aged 12 and over) from each of the selected households was randomly chosen. A 'drop and collect' method was employed: selected residents were given a paper version of the survey to self-complete, and the survey was collected at a pre-arranged date. The final sample included 23,855 respondents (49.1\% response rate). A detailed description of the method is reported elsewhere [30].

In the present analysis, respondents aged 17 or younger $(n=1159)$ were excluded, along with 823 cases with incomplete data for alcohol consumption, leaving a sample of 21,873 for analysis. The focus on adults $(18+)$ is consistent with the age parameters attached to the lifetime low risk and single occasion low risk guidelines [3].

\section{Measures}

\section{Alcohol use and risk levels}

Past year alcohol use was based on whether the respondent had consumed alcohol in the past 12 months (yes/no). Patterns of drinking were measured by the graduatedfrequency method, which asks about the frequency of drinking eight different quantities (ranging down from $20+$ drinks to none) in the past year. An annual total volume was calculated from the graduated-frequency responses [31] and amounts reported ranged from zero to 7665 drinks.

Respondents were classified as abstainers if they reported no alcohol use in the past year or had a total volume of zero $(n=4796)$. This paper does not differentiate between never drinkers and former drinkers.

Two measures were used to classify respondents who had consumed alcohol in the past year: lifetime low risk (LLR) and single occasion low risk (SOLR). These measures were aligned with the 2009 guidelines [3]. Respondents with a total volume of 1-730 drinks were classified as lifetime low-risk drinkers, which is consistent with the average of below two drinks per day (over a single year) interpretation of the LLR guideline [32]; 13,081 respondents met this.

SOLR equated to the second guideline - drinking no more than four drinks on any single occasion [3] in the past year; 9194 respondents met this. A total of 8734 
respondents drank in accordance with both guidelines; this category is hereafter referred to as 'low risk'. Respondents drinking in excess of the thresholds (i.e., total volume $>730$, or $5+$ drinks on a single occasion) were categorised as 'at risk' and excluded from the main analysis. As Table 1 shows, $22.6 \%$ of adult Australians had not consumed alcohol in the previous year, and 37.0\% drink at low-risk levels, taking into account both average volume and episodic drinking. These two groups were used in the main analysis.

Socio-demographic variables included sex, age (in age groups), country of birth, marital status, number of dependent children in the household aged 14 and under and children older than 14 who are not financially independent and whom the respondent is parent or guardian for, highest educational qualification, pre-tax annual household income from all sources, neighbourhood disadvantage and geographical location.

Neighbourhood disadvantage was based on multiple socio-economic indicators of a neighbourhood and is expressed as quintiles [33]. The first quintile equates to the $20 \%$ most disadvantaged neighbourhoods and the fifth quintile the $20 \%$ least disadvantaged neighbourhoods. Geographical location was formulated from the Australian Statistical Geography Standard for Remoteness Area structure whereby postcodes are used to classify areas as: major cities, inner regional, outer regional, remote and very remote [34]. The last three area types were collapsed in this paper.

\section{Statistical analysis}

Logistic regression was used to examine the sociodemographic correlates of low-risk drinking compared to abstaining. Data were weighted to address any imbalances in the probability of a respondent being selected and to ensure that the data are as representative as possible of the general Australian population. Results from the bivariate and multivariate analyses are presented as odds ratios (OR) with $95 \%$ confidence intervals $(95 \% \mathrm{CI})$. OR are based on weighted data; sample numbers are unweighted. Analyses were conducted using Stata version 14.0. Sexspecific models have not been reported, as preliminary analysis found few differences between men and women in socio-demographic prediction of low-risk drinking versus abstention.

\section{Results}

Table 2 shows household income was a strong predictor of low-risk drinking compared to abstention, controlling for all other variables. Low-risk drinkers were significantly more likely to be in a high household income category compared to those with a low income. Residing in a neighbourhood with a lower level of disadvantage increased the likelihood of being a low-risk drinker, as did the attainment of a post-secondary school qualification. Older age (40-64 and 65+ years compared to 18-24 years) increased the likelihood of being a low-risk drinker, whereas widowed adults were more likely than those in a marriage-type relationship to abstain rather than drink at low-risk once other factors were controlled for. Being born in Australia was positively associated with low-risk drinking as was living in innerregional area. No significant difference was found between sex and drinking status.

There were some differences between the bivariate and multivariate analyses. The following characteristics were significantly associated with low-risk drinking at the bivariate level, but not at the multivariate level: being 25-39 years old; never being married or being separated; and having more than one dependent child in the household. The differences were possibly due to an interaction between age and marital status.

\section{Discussion}

This paper compares socio-demographic characteristics of Australian adults who drink at low-risk levels with abstainers. Multivariate findings indicate that drinking in accordance with the Australian drinking guidelines, as opposed to abstaining from alcohol, was associated with individual and community level characteristics. Specifically, being older, not widowed, Australian-born, having a higher income and higher-level education, residing in a less disadvantaged area and living in an inner regional area.

Our finding that higher socio-economic status increases the likelihood of low-risk drinking as opposed to abstaining is consistent with studies of older adults' alcohol consumption $[18,23]$. It suggests that further education and greater financial means are associated with a social position where drinking is potentially more affordable and where moderation is socially acceptable [35, 36].

Table 1 Percentage prevalence of lifetime risk by single occasion risk as per 2009 NHMRC Guidelines, Australians aged 18+, weighted 2013 national survey

\begin{tabular}{lllll}
\hline Lifetime risk & Abstainer & Low risk ( $<5$ drinks on a single occasion) & At risk (5+ drinks on a single occasion) & Total \\
\hline Abstainer & 22.6 & - & - & 22.6 \\
Low risk ( $<=2$ drinks per day, on average) & - & 37.0 & 22.1 & 59.1 \\
At risk ( $>2$ drinks per day, on average) & - & 1.7 & 16.6 & 18.3 \\
Total & 22.6 & 38.7 & 38.7 & 100 \\
\hline
\end{tabular}


Table 2 Bivariate and multivariate logistic regression models predicting low-risk drinkers (8434) compared to abstainers (4796)

\begin{tabular}{|c|c|c|c|c|}
\hline & \multicolumn{2}{|c|}{ Bivariate } & \multicolumn{2}{|c|}{ Multivariate $^{a}$} \\
\hline & $\overline{\mathrm{OR}}$ & $95 \% \mathrm{Cl}$ & $\overline{\mathrm{OR}}$ & $95 \% \mathrm{Cl}$ \\
\hline \multicolumn{5}{|l|}{ Sex } \\
\hline Male & 1 (Ref) & & 1 (Ref) & \\
\hline Female & 1.02 & $(0.93,1.11)$ & 1.07 & $(0.97,1.19)$ \\
\hline \multicolumn{5}{|l|}{ Age } \\
\hline $18-24$ & 1 (Ref) & & 1 (Ref) & \\
\hline $25-39$ & $1.46^{* * *}$ & $(1.19,1.79)$ & 1.20 & $(0.92,1.57)$ \\
\hline $40-64$ & $1.98^{* * *}$ & $(1.63,2.40)$ & $1.56^{* * *}$ & $(1.23,2.07)$ \\
\hline 65 and older & $1.35^{* *}$ & $(1.11,1.65)$ & $1.58^{* *}$ & $(1.18,2.06)$ \\
\hline \multicolumn{5}{|l|}{ Country of birth } \\
\hline Australian & $1.98^{* * *}$ & $(1.81,2.16)$ & $1.85^{* * *}$ & $(1.68,2.05)$ \\
\hline Other & 1 (Ref) & 1 (Ref) & 1 (Ref) & 1 (Ref) \\
\hline \multicolumn{5}{|l|}{ Marital status } \\
\hline Never married & $0.68^{* * *}$ & $(0.59,0.77)$ & 0.86 & $(0.73,1.02)$ \\
\hline Widowed & $0.54^{* * *}$ & $(0.46,0.63)$ & $0.67^{* * *}$ & $(0.55,0.81)$ \\
\hline Divorced/separated & $0.83^{* *}$ & $(0.72,0.94)$ & 0.95 & $(0.82,1.10)$ \\
\hline Married/defacto/life partner & 1 (Ref) & & 1 (Ref) & \\
\hline \multicolumn{5}{|c|}{ Dependent children in household ${ }^{b}$} \\
\hline None & 1 (Ref) & & 1 (Ref) & \\
\hline One or more & $1.12^{*}$ & $(1.02,1.23)$ & 0.93 & $(0.83,1.04)$ \\
\hline \multicolumn{5}{|l|}{ Highest qualification } \\
\hline Yr 13 or equivalent or less & 1 (Ref) & & 1 (Ref) & \\
\hline Certificate or Diploma & $1.56^{* * *}$ & $(1.41,1.73)$ & $1.43^{* * *}$ & $(1.28,1.60)$ \\
\hline Bachelor or higher & $1.90^{* * *}$ & $(1.70,2.12)$ & $1.48^{* * *}$ & $(1.30,1.69)$ \\
\hline \multicolumn{5}{|l|}{ Household annual income } \\
\hline Low (\$51,999 or less) & 1 (Ref) & & 1 (Ref) & \\
\hline Middle $(\$ 52,000-\$ 103,999)$ & $1.84^{* * *}$ & $(1.63,2.08)$ & $1.68^{* * *}$ & $(1.46,1.93)$ \\
\hline High $(\$ 104,000+)$ & $2.96^{* * *}$ & $(2.59,3.39)$ & $2.34^{* * *}$ & $(1.99,2.74)$ \\
\hline \multicolumn{5}{|l|}{ Neighbourhood disadvantage $^{c}$} \\
\hline 1 (lowest) & 1 (Ref) & & 1 (Ref) & \\
\hline 2 & $1.42^{* * *}$ & $(1.24,1.62)$ & $1.23^{* *}$ & $(1.07,1.42)$ \\
\hline 3 & $1.75^{* * *}$ & $(1.52,2.00)$ & $1.48^{* * *}$ & $(1.27,1.71)$ \\
\hline 4 & $2.18^{* * *}$ & $(1.91,2.49)$ & $1.71^{* * *}$ & $(1.48,1.98)$ \\
\hline 5 (highest) & $2.67^{* * *}$ & $(2.32,3.08)$ & $2.19^{* * *}$ & $(1.86,2.58)$ \\
\hline \multicolumn{5}{|l|}{ Geographical location } \\
\hline Metro & 1 (Ref) & & 1 (Ref) & \\
\hline Inner regional & $1.29^{* * *}$ & $(1.15,1.45)$ & $1.29 * * *$ & $(1.13,1.47)$ \\
\hline Outer regional/remote & 0.99 & $(0.87,1.3)$ & 1.11 & $(0.96,1.29)$ \\
\hline
\end{tabular}

\footnotetext{
adds ratios (ORs) were adjusted for all the variables listed in this table
}

${ }^{\mathrm{b}}$ Dependent children are children aged 0 to 14 and those aged over 14 who are not financially independent for whom the respondent is the parent or guardian of

${ }^{c}$ Neighbourhood disadvantage equates to the Socio-Economic Index For Areas (SEIFA; high scores equate to low levels of disadvantage) Outcome variable: low-risk ( $n=8434)(1)$, abstainer $(n=4796)(0)$

Ns are based on unweighted data and estimates (\%, ORs and confidence intervals (Cl) are based on weighted data. Cl: $p<.05$ is ; $p<.01$ is **; $p<.001$ is *** 
Drinking behaviour is widely considered to be agerelated, and often characterised by heavier episodic drinking during early adulthood, more frequent but lower overall consumption in mid-to-late adulthood [11,37], followed by increased prevalence of abstinence in later life [23]. Recent studies have also shown that the transition to abstinence in later life is not as widespread as in previous generations [19]. Thus, our finding that older adults are more likely to report low-risk drinking than abstinence, after all other factors are controlled for, was not unexpected. It may also be the case that low-risk drinking is a norm violation for 1824-year-olds - they are either heavier drinkers [38] or, as recent data suggest, abstaining from alcohol [1]. Widowed adults, as opposed to those with a partner, were more likely to abstain than consume alcohol at low-risk levels. This finding is supported by previous studies [25] and is consistent with the argument that marital-type relationships facilitate the consumption of alcohol [39, 40]. No significant difference was found by sex in drinking status in the current study at either the bivariate or the multivariate level. Given women are more likely to abstain, and they are also less likely to drink at risky levels [41], it's not unexpected that no significant difference was found.

The study's limitations stem from the cross-sectional data source which does not allow causal inferences to be drawn. Also, alcohol use was compiled from self-report items, including the standard graduated-frequency questions; all items referred to a 12-month recall window and respondents were asked to answer in terms of standard drinks, as this unit was explained to them. All these aspects have the potential to introduce recall measurement error, which may yield an underestimate of consumption [42-44] and thus presumably an overestimate of abstinence and low-risk drinking.

The response rate of $48.1 \%$, although comparable to previous waves of the NDSHS [45], presents the potential of non-response bias. For example, a comparison of the 4179 respondents who returned a blank or unusable 2013 NDSH survey with those who returned a completed survey $(23,855)$ revealed higher proportions of men and younger adults among the former [30]. Given the two attributes (male; younger) are commonly associated with heavy drinking patterns (e.g., [46]), it is possible that demographic differences between respondents and non-respondents may have biased alcohol estimates. There is also evidence to suggest abstainers may be over-represented amongst non-respondents [47].

Despite these limitations, gaining a better understanding of the social location of low-risk drinkers, as distinct from abstainers can be seen as a first step towards learning more about the social norms and stability of low-risk alcohol use. This is important in view of the increasing weight of evidence that low levels of alcohol consumption are not risk free. Furthermore, increasing our understanding of low-risk drinkers may provide additional ways to frame discussions around less harmful drinking patterns and promote this as an achievable and acceptable practice, especially if abstinence is not perceived as a viable outcome.

\section{Conclusion}

At different points in Australia's history, social and political directives have shaped low-risk and non-drinking aspirations [27], yet few studies have afforded actual practices in these areas much attention. By comparing low-risk drinkers with abstainers, this paper identifies important sociodemographic characteristics of both groups. Given the differences that emerged, we question the appropriateness of treating low-risk drinkers and abstainers as a single comparison group in non-mortality or morbidity studies investigating risky drinking. Differentiating the demographic characteristics of abstainers and low-risk drinkers here and in future studies will support targeted interventions.

\section{Abbreviations}

ADA: Australian Data Archive; Cl: Confidence intervals; LLR: Lifetime low risk; NDSHS: National Drug Strategy Household Survey; NHMRC: National Health and Medical Research Council; OR: Odds ratios; SEIFA: Socio-Economic Index For Areas; SOLR: Single occasion low risk

\section{Acknowledgements}

Not applicable.

\section{Authors' contributions}

The research underpinning this publication was undertaken by JM while completing a PhD at La Trobe University, Melbourne, Victoria. JM contributed to the formulation of the research questions and conducted the literature review, data analysis, manuscript drafting; SML contributed the formulation of the research questions and critical revisions of the paper; RR contributed the formulation of the research questions and critical revisions of the paper; $\mathrm{SC}$ contributed the formulation of the research questions, assisted with data analysis and interpretation, and critical revisions of the paper. All authors read and approved the final version of the manuscript submitted for publication.

\section{Funding}

JM is supported by an Australian Government Research Training Program Stipend Scholarship (administered by La Trobe University) and a top-up scholarship from Australian Rechabite Foundation. SC is a recipient of a Discovery Early Career Research Award fellowship from the Australian Research Council (DE180100016). RR's time on this study was funded by the Foundation for Alcohol Research and Education, an independent, charitable organization working to prevent the harmful use of alcohol in Australia (www.fare.org.au). The funders had no role in the study's conceptualization, data collection, analysis or interpretation, or writing of this manuscript.

\section{Availability of data and materials}

The Australian Institute of Health and Welfare manage the data collection and dissemination of the National Drug Strategy Household Survey and we are grateful to them for facilitating access to the data via the Australian Data Archive (ADA). The data was accessed through a formal application submitted to the ADA (https://ada.edu.au/accessing-data/).

\section{Ethics approval and consent to participate}

A negligible risk application was approved by the Latrobe University College of Science, Health and Engineering Human Ethics Sub-Committee (S16/15; approval 2 March 2016). The negligible risk status was appropriate as researchers used secondary data provided in a non-identifiable format. 


\section{Competing interests}

The authors declare that they have no competing interests.

\section{Author details}

${ }^{1}$ Centre for Alcohol Policy Research, School of Psychology and Public Health, La Trobe University, Bundoora, Victoria 3086, Australia. ${ }^{2}$ School of Allied Health, Human Services and Sport, La Trobe University, Bundoora, Victoria 3086, Australia. ${ }^{3}$ Centre for Social Research on Alcohol and Drugs, Department of Public Health Sciences, Stockholm University, Stockholm 106 91, Sweden

\section{Received: 19 September 2019 Accepted: 31 December 2019 Published online: 10 January 2020}

\section{References}

1. Australian Institute of Health and Welfare. National Drug Strategy Household Survey 2016: detailed findings. Drug statistics series no 31 Cat no PHE 214. Canberra: AlHW; 2017.

2. Australian Bureau of Statistics. National Health Survey: first results 2014-15. Canberra: Commonwealth of Australia; 2015.

3. National Health Medical Research Council. Australian guidelines to reduce health risks from drinking alcohol. Canberra: NHMRC, Australian Government; 2009.

4. National Drug Strategy Household Survey 2016: alcohol chapter supplementary data tables [Internet]. 2017 [cited 22 May 2019]. Available from: https://www.aihw.gov.au/reports/illicit-use-of-drugs/2016-ndshsdetailed/data.

5. Vafeas C, Graham R, de Jong G, Sharp J, Ngune I, Maes S. Alcohol consumption patterns of older adults: a study in a regional town in Western Australia. Contemp Nurse. 2017;53(6):647-57 https://doi.org/10.1080/ 10376178.2017.1421051.

6. Chen WY, Rosner B, Hankinson SE, Colditz GA, Willett WC. Moderate alcohol consumption during adult life, drinking patterns, and breast cancer risk. J Am Med Assoc. 2011;306(17):1884-90 https://doi.org/10.1001/jama.2011. 1590.

7. Taylor AW, Dal Grande E, Wu J, Shi ZM, Campostrini S. Ten-year trends in major lifestyle risk factors using an ongoing population surveillance system in Australia. Popul Health Metrics. 2014;12 https://doi.org/10.1186/s12963014-0031-z.

8. Matthews S, Dietze P, Room R, Chikritzhs T, Jolley D. The social location of heavy episodic alcohol consumption in the Victorian population. Drug Alcohol Rev. 2013;32(2):157-61 https://doi.org/10.1111/j.1465-3362.2012. 00511.x.

9. Brumby S, Kennedy A, Chandrasekara A. Alcohol consumption, obesity, and psychological distress in farming communities: an Australian study. J Rural Health. 2013;29(3):311-9 https://doi.org/10.1111/jrh.12001.

10. Giskes K, Turrell G, Bentley R, Kavanagh A. Individual and household-level socioeconomic position is associated with harmful alcohol consumption behaviours among adults. Aust N Z J Public Health. 2011;35(3):270-7 https://doi.org/10.1111/j.1753-6405.2011.00683.x.

11. Taylor AW, Campostrini S, Beilby J. Demographic trends in alcohol use: the value of a surveillance system. Am J Health Behav. 2013;37(5):641-53 https://doi.org/10.5993/AJHB.37.5.8.

12. Shakeshaft A, Petrie D, Doran C, Breen C, Sanson-Fisher R. An empirical approach to selecting community-based alcohol interventions: combining research evidence, rural community views and professional opinion. BMC Public Health. 2012;12:11 https://doi.org/10.1186/1471-2458-12-25.

13. Powers JR, Loxton D, Anderson AE, Dobson AJ, Mishra GD, Hockey R, et al. Changes in smoking, drinking, overweight and physical inactivity in young Australian women 1996-2013. Health Promot J Austr. 2017;28(3):255-9 https://doi.org/10.1071/HE16085.

14. Skov SJ, Chikritzhs TN, Li SQ, Pircher S, Whetton S. How much is too much? Alcohol consumption and related harm in the Northern Territory. Med J Aust. 2010;193(5):269-72 https://doi.org/10.5694/j.1326-5377.2010.tb03905.x.

15. Coulson C, Williams L, Henry M, Berk M, Lubman D, Brennan S, et al. Patterns of alcohol use and associated physical and lifestyle characteristics according to new Australian guidelines. Aust N Z J Psychiatry. 2010;44(10): 946-51 https://doi.org/10.3109/00048674.2010.495051.

16. Powers JR, Young AF. Longitudinal analysis of alcohol consumption and health of middle-aged women in Australia. Addiction. 2008;103(3):424-32 https://doi.org/10.1111/j.1360-0443.2007.02101.x.
17. Patterson KAE, Cleland V, Venn A, Blizzard L, Gall S. A cross-sectional study of geographic differences in health risk factors among young Australian adults: the role of socioeconomic position. BMC Public Health. 2014;14(1): 720-38 https://doi.org/10.1186/1471-2458-14-1278.

18. French DJ, Sargent-Cox KA, Kim S, Anstey KJ. Gender differences in alcohol consumption among middle-aged and older adults in Australia, the United States and Korea. Aust N Z J Public Health. 2014;38(4):332-9 https:/doi.org/ 10.1111/1753-6405.12227.

19. Burns RA, Birrell CL, Steel D, Mitchell P, Anstey KJ. Alcohol and smoking consumption behaviours in older Australian adults: prevalence, period and sociodemographic differentials in the DYNOPTA sample. Soc Psychiatry Psychiatr Epidemiol. 2013;48(3):493-502 https://doi.org/10.1007/s00127-012-0558-x.

20. Bonevski B, Regan T, Paul C, Baker AL, Bisquera A. Associations between alcohol, smoking, socioeconomic status and comorbidities: evidence from the 45 and up study. Drug Alcohol Rev. 2014;33(2):169-76 https://doi.org/ 10.1111/dar.12104.

21. Donato-Hunt C, Munot S, Copeland J. Alcohol, tobacco and illicit drug use among six culturally diverse communities in Sydney. Drug Alcohol Rev. 2012;31(7):881-9 https://doi.org/10.1111/j.1465-3362.2012.00417.x.

22. Herd D. Subgroup differences in drinking patterns among black and white men: results from a national survey. J Stud Alcohol. 1990;51(3):221-32 https://doi.org/10.15288/jsa.1990.51.221.

23. Blazer $\mathrm{D}, \mathrm{Wu} \mathrm{L}-\mathrm{T}$. The epidemiology of at-risk and binge drinking among middle-aged and elderly community adults: National Survey on drug use and health. Am J Psychiatry. 2009;166(10):1162-9 https://doi.org/10.1176/ appi.ajp.2009.09010016.

24. Rundberg J, Lidfeldt J, Nerbrand C, Samsioe G, Romelsjö A, Öjehagen A. Abstinence, occasional drinking and binge drinking in middle-aged women: the Women's health in Lund area (WHILA) study. Nordic Journal of Psychiatry. 2008:62(3):186-91 https://doi.org/10.1080/08039480801959216.

25. San Jose B, Lagiou P, Chloptsios Y, Trichopoulou A. Sociodemographic correlates of abstinence and excessive drinking in the Greek population. Subst Use Misuse. 2001;36(4):463-75 https://doi.org/10.1081/JA-100102637.

26. Böckerman P, Hyytinen A, Maczulskij T. Alcohol consumption and long-term labor market outcomes. Health Econ. 2017;26(3):275-91 https://doi.org/10. 1002/hec.3290.

27. Room R. The long reaction against the wowser: the prehistory of alcohol deregulation in Australia. Health Sociol Rev. 2010;19(2):151-63 https://doi. org/10.5172/hesr.2010.19.2.151.

28. Department of Health and Ageing. National Binge Drinking Strategy 20082012: Australian Government; 2008 [Available from: http://www.alcohol.gov. au/internet/alcohol/publishing.nsf/Content/cli.

29. Jefferson A. "National Drug Strategy Household Survey, 2013", doi: https:// doi.org/10.4225/87/USGEQS, ADA Dataverse, V1. 2018.

30. Roy Morgan Research. National Drug Strategy Household Survey 2013: Final technical report. Melbourne: Roy Morgan Research; 2014.

31. Livingston M, Room R. Variations by age and sex in alcohol-related problematic behaviour per drinking volume and heavier drinking occasion. Drug Alcohol Depend. 2009;101(3):169-75 https://doi.org/10.1016/j. drugalcdep.2008.12.014.

32. Australian Institute of Health and Welfare. Measuring alcohol risk in the 2010 National Drug Strategy Household Survey: implementation of the 2009 alcohol guidelines. Canberra: AlHW; 2011.

33. Australian Bureau of Statistics. Socio-economic indexes for areas (SEIFA): technical paper. Canberra: Commonwealth of Australia; 2013.

34. Australian Bureau of Statistics. Australian statistical geography standard (ASGS): volume 5 - remoteness structure (July 2011). Canberra: Commonwealth of Australia; 2012.

35. Schmidt L, Mäkelä P, Rehm J, Room R. Alcohol: equity and social determinants. In: Blas K, Kurup A, editors. Equity, social determinants and public health programmes. Switzerland: World Health Organization; 2010. p. $11-30$.

36. Lui CK, Chung PJ, Ford CL, Grella CE, Mulia N. Drinking behaviors and life course socioeconomic status during the transition from adolescence to adulthood among whites and blacks. J Stud Alcohol Drugs. 2015;76(1):68 https://doi.org/10.15288/jsad.2015.76.68.

37. Delker E, Brown Q, Hasin DS. Alcohol consumption in demographic subpopulations: an epidemiologic overview. Alcohol Res: Current Reviews. 2016;38(1):7-15 https:/www.ncbi.nlm.nih.gov/pmc/articles/PMC4872616/.

38. Robertson K, Tustin K. Students who limit their drinking, as recommended by national guidelines, are stigmatized, ostracized, or the subject of peer 
pressure: limiting consumption is all but prohibited in a culture of intoxication. Subst Abuse: Research Treatment. 2018;12. https://doi.org/10 1177/1178221818792414.

39. Windle M, Windle RC. A prospective study of alcohol use among middleaged adults and marital partner influences on drinking. J Stud Alcohol Drugs. 2014;75(4):546 https://doi.org/10.15288/jsad.2014.75.546.

40. Demers A, Bisson J, Palluy J. Wives' convergence with their husbands' alcohol use: social conditions as mediators. J Stud Alcohol. 1999;60(3):36877 https://doi.org/10.15288/jsa.1999.60.368.

41. Wilsnack RW, Wilsnack SC, Kristjanson AF, Vogeltanz-Holm ND, Gmel G Gender and alcohol consumption: patterns from the multinational GENACIS project. Addiction. 2009;104(9):1487-500 https://doi.org/10.1111/j.1360-0443. 2009.02696.X.

42. Stockwell T, Zhao J, Greenfield T, Li J, Livingston M, Meng Y. Estimating under-and over-reporting of drinking in national surveys of alcohol consumption: identification of consistent biases across four Englishspeaking countries. Addiction. 2016;111(7):1203-13 https://doi.org/10.1111/ add. 13373.

43. Livingston M, Callinan S. Underreporting in alcohol surveys: whose drinking is underestimated? J Stud Alcohol Drugs. 2015;76(1):158-64 https://doi.org/ 10.15288/jsad.2015.76.158.

44. Stockwell T, Donath S, Cooper-Stanbury M, Chikritzhs T, Catalano P, Mateo C. Under-reporting of alcohol consumption in household surveys: a comparison of quantity-frequency, graduated-frequency and recent recall. Addiction. 2004;99(8):1024-33 https://doi.org/10.1111/j.1360-0443.2004. 00815.x.

45. Australian Institute of Health and Welfare. National Drug Strategy Household Survey: Detailed report 2013. Drug statistics series no 28 cat no PHE 183. Canberra: AlHW; 2014

46. Roxburgh A, Miller P, Dunn M. Patterns of alcohol, tobacco and cannabis use and related harm in city, regional and remote areas of Australia. Int Drug Policy. 2013;24(5):488-91 https://doi.org/10.1016/j.drugpo.2013.02.001

47. Lahaut VM, Jansen HA, Van de Mheen D, Garretsen HF. Non-response bias in a sample survey on alcohol consumption. Alcohol Alcohol. 2002;37(3): 256-60 https://doi.org/10.1093/alcalc/37.3.256

\section{Publisher's Note}

Springer Nature remains neutral with regard to jurisdictional claims in published maps and institutional affiliations.

Ready to submit your research? Choose BMC and benefit from:

- fast, convenient online submission

- thorough peer review by experienced researchers in your field

- rapid publication on acceptance

- support for research data, including large and complex data types

- gold Open Access which fosters wider collaboration and increased citations

- maximum visibility for your research: over $100 \mathrm{M}$ website views per year

At $\mathrm{BMC}$, research is always in progress.

Learn more biomedcentral.com/submissions 